NBER WORKING PAPER SERIES

\title{
AFFECTIVE POLARIZATION DID NOT INCREASE DURING THE CORONAVIRUS PANDEMIC
}

\author{
Levi Boxell \\ Jacob Conway \\ James N. Druckman \\ Matthew Gentzkow \\ Working Paper 28036 \\ http://www.nber.org/papers/w28036
NATIONAL BUREAU OF ECONOMIC RESEARCH
1050 Massachusetts Avenue
Cambridge, MA 02138
October 2020

We acknowledge funding from the Stanford Institute for Economic Policy Research (SIEPR), Northwestern University, the John S. and James L. Knight Foundation, the Sloan Foundation, the Institute for Humane Studies, and the National Science Foundation (grant number: DGE-1656518). Anna Wang provided excellent research assistance.The views expressed herein are those of the authors and do not necessarily reflect the views of the National Bureau of Economic Research.

NBER working papers are circulated for discussion and comment purposes. They have not been peerreviewed or been subject to the review by the NBER Board of Directors that accompanies official NBER publications.

(c) 2020 by Levi Boxell, Jacob Conway, James N. Druckman, and Matthew Gentzkow. All rights reserved. Short sections of text, not to exceed two paragraphs, may be quoted without explicit permission provided that full credit, including $(\odot)$ notice, is given to the source. 
Affective Polarization Did Not Increase During the Coronavirus Pandemic Levi Boxell, Jacob Conway, James N. Druckman, and Matthew Gentzkow NBER Working Paper No. 28036

October 2020

JEL No. P16

\section{ABSTRACT}

We document trends in affective polarization during the coronavirus pandemic. In our main measure, affective polarization is relatively flat between July 2019 and February 2020, then falls significantly around the onset of the pandemic. Two other data sources show no evidence of an increase in polarization around the onset of the pandemic. Finally, we show in an experiment that priming respondents to think about the coronavirus pandemic significantly reduces affective polarization.

Levi Boxell

Stanford University, Department of Economics 579 Jane Stanford Way

Stanford, CA 94305

Lboxell@stanford.edu

Jacob Conway

Stanford University

Department of Economics

579 Jane Stanford Way

Stanford, CA 94305

jcconway@stanford.edu
James N. Druckman

Northwestern University

601 University Place

Evanston, IL 60208

druckman@northwestern.edu

Matthew Gentzkow

Department of Economics

Stanford University

579 Jane Stanford Way

Stanford, CA 94305

and NBER

gentzkow@stanford.edu 


\section{Introduction}

In the early US coronavirus pandemic, the response of politicians and media outlets in the US diverged sharply along partisan lines (Carothers 2020; Simonov et al. 2020). Perhaps as a response,

partisan differences have also emerged among individual citizens in both beliefs about the severity of the pandemic and social distancing responses (Allcott et al. 2020). Affective polarization-the extent to which partisans feel more negatively toward the opposing political party than toward their own-is also at a multi-decade high (Iyengar et al. 2019).

In this context, commentators have expressed concern that the coronavirus pandemic may be driving Americans further apart (Carothers 2020; Tierney 2020; Victor 2020). Others have noted that such a national emergency could reduce polarization by bringing partisans together in facing a common threat (Quarcoo and Kleinfeld 2020; Van Bavel et al. 2020). Shifting media consumption patterns may also influence polarization (Ritter 2020).

We use multiple data sources to document trends in affective polarization during the coronavirus pandemic. Two of three data sources suggest that affective polarization declined with the onset of the coronavirus, with the third suggesting neither a decline nor an increase. A survey experiment adds further evidence in support of a decline.

\section{Results}

\subsection{Descriptive Trends in Affective Polarization}

Panel A of Figure 1 reports trends in our measure of affective polarization towards partisans using Nationscape data that covers more than 300,000 interviews between July 2019 and July 2020. Panel A shows that, prior to the rise of the coronavirus in the US, affective polarization was relatively flat and this flat trend extends back to July 2019. However, after the first coronavirus-related death, affective polarization begins to decline. In the aftermath of George Floyd's death, affective polarization increases_-nearly returning to pre-pandemic levels.

Panels $\mathrm{B}$ and $\mathrm{C}$ of Figure 1 reports trends in affective polarization using alternative data sources. One series (Panel B) indicates a large and statistically significant decline in affective polarization while the other series (Panel C) indicates a small and insignificant increase. 


\subsection{Survey Experiment}

We also conduct a survey experiment with three treatment conditions and 1503 respondents. In the coronavirus treatment, respondents are asked to read two news article excerpts that cover the initial phases of the coronavirus pandemic and to reflect on their own experiences and faith in the United States' ability to address the pandemic at its onset. ${ }^{1}$ In the placebo treatment, respondents are asked to perform the same exercise but for Prince Harry and Meghan Markle's financial separation from the UK royal family. In the pure control group, respondents are not asked to perform any exercise.

Panel A of Figure 2 reports the estimated treatment effects on the difference between ownparty and other-party views. Relative to the pure control group, the coronavirus prime reduced an index of affective polarization by 3.8 units (p-value $=0.042$ ) on a 0 to 100 scale. The coronavirus treatment effect is larger in magnitude than the placebo's, though this difference is not statistically significant ( $\mathrm{p}$-value $=0.290$ ). Panel $\mathrm{B}$ focuses on feelings towards the other party. The coronavirus prime improved an index of feelings towards the other party by 3.5 units ( $p$-value $=0.005)$ and this effect is significantly larger than the placebo's ( $\mathrm{p}$-value $=.046$ ). Similar results are observed for many of the individual components of the index.

Despite the coronavirus treatment effects reducing polarization, more than two-thirds of our survey respondents indicated that the coronanavirus has made the public more politically divided.

\section{Discussion}

One potential mechanism for the decline is the creation of a new sense of unity in response to a national threat. Though elite messaging and observed social distancing behaviors exhibited important partisan differences (Allcott et al. 2020), focusing only on differences in behaviors masks the overwhelming unity in early-stage responses. Between January 2018 and March 2020, the share of Americans indicating "we're all in it together" increased from 63 percent to 90 percent (More in Common 2020).

Shifts in news consumption, particularly local news consumption, may be another contributing mechanism. A poll series by Gallup shows that between December 2019 and March 2020, the share of Americans paying a "great deal" of attention to local news increased from 22 percent to 44 percent (Ritter 2020). Both Republicans and Democrats consider local news to be less ideologi-

\footnotetext{
${ }^{1}$ See SI appendix for news article excerpts.
} 
cally biased, and there is evidence that local news attenuates polarization (Darr et al. 2018; Brenan 2019). National outlets may have also shifted news coverage away from other political issues to focus on the pandemic.

Moreoever, when facing a global pandemic, Americans may be preoccupied with other concernslowering the general salience of political divisions.

While we cannot cleanly separate the causal effect of the coronavirus pandemic from similarly timed events, the combination of the descriptive trends and the survey priming experiment suggest that the coronavirus pandemic did not increase and may have even decreased affective polarization in the United States.

\section{Material and Methods}

Across datasets, we define affective polarization to be the weighted average of individual's feelings towards one's own party minus feelings towards the other party. We include leaners, but exclude pure independents. We use survey weights when available consistently across a given data series. We apply an affine transformation to all measures of affect so they range between 0 and 100 .

For the survey, we recruited 1503 respondents on Bovitz Inc.'s survey panel between September 29, 2020 and October 4, 2020, and we exclude 88 respondents that failed an attention check. The protocol was approved as exempt by Northwestern University's IRB (STU00212339), and informed consent was obtained at the beginning of the survey. The survey analysis was pre-registered at aspredicted.org (\#48474). For each category of affect questions (feelings thermometer, trust, perceived traits, and social distance), we first rescaled responses to range between 0 and 100 before taking the average across responses within a given category for each individual. We then take the average across categories to construct the index for each respondent. There are one, one, eight, and three questions associated with the feeling thermometer, trust, perceived traits, and social distance categories respectively.

Replication code and data from Nationscape, Druckman et al. (2020), and our own survey experiment will be posted upon final publication at https://osf.io/dra7s/. Data from the American National Election Study is available at https://electionstudies.org/data-center/. The survey instruments are available in the SI appendix. 


\section{References}

Allcott, Hunt, Levi Boxell, Jacob Conway, Matthew Gentzkow, Michael Thaler, and David Yang. 2020. Polarization and public health: Partisan differences in social distancing during the coronavirus pandemic. Journal of Public Economics. Forthcoming.

Brenan, Megan. 2019. Local news media considered less biased than national news. Gallup. Accessed at https://news.gallup.com/poll/268160/local-news-media-considered-less-biased-national-news.aspx.

Carothers, Thomas. 2020. The United States: Presidential leadership, polarization, and the coronavirus. Carnegie Endowment for International Peace. Accessed at https://carnegieendowment.org/2020/04/28/unitedstates-presidential-leadership-polarization-and-coronavirus-pub-81643

Darr, Joshua P., Matthew P. Hitt, and Johanna L. Dunaway. Newspaper closures polarize voting behavior. Journal of Communication. 68(8): 1007-1028.

Druckman, James, Samara Klar, Yanna Krupnikov, and Matthew Levendusky. 2020. How affective polarization shapes Americans' political beliefs: A study of response to the COVID-19 pandemic. Journal of Experimental Political Science. Forthcoming.

Iyengar, Shanto, Yphtach Lelkes, Matthew Levendusky, Neil Malhotra, and Sean J. Westwood. 2019. The origins and consequences of affective polarization in the United States. Annual Review of Political Science. 22: 129-146.

More in Common. 2020. Covid-19: Polarization and the pandemic. Accessed at https://www.moreincommon.com/media tribes_covid-19-polarization-and-the-pandemic-as-released-4-3-20.pdf.

Quarcoo, Ashley and Rachel Kleinfeld. 2020. Can the coronavirus heal polarization? Carnegie Endowment for International Peace. Accessed at https://carnegieendowment.org/2020/05/01/can-coronavirus-healpolarization-pub-81704.

Ritter, Zacc. 2020. Amid pandemic, news attention spikes; media favorability flat. Gallup. Accessed at https://news.gallup.com/opinion/gallup/307934/amid-pandemic-news-attention-spikes-media-favorabilityflat.aspx.

Simonov, Andrey, Szymon K. Sacher, Jean-Pierre H. Dubé, and Shirsho Biswas. 2020. The persuasive effect of Fox News: Non-compliance with social distancing during the Covid-19 pandemic. Working Paper.

Tierney, Dominic. 2020. Not even the coronavirus will unite America. The Atlantic. Accessed at https://www.theatlantic.। even-coronavirus-will-unite-america/608698/.

Van Bavel, Jay J., Katherine Baicker, Paulo S. Boggio, Valerio Capraro, Aleksandra Cichocka, Mina Cikara, Molly J. Crockett et al. 2020. Using social and behavioural science to support COVID-19 pandemic response. Nature Human Behaviour. 4: 460-471.

Victor, Jennifer Nicoll. 2020. The pandemic makes politics worse: The Unites States as a case study. AlJazeera. Accessed at https://studies.aljazeera.net/en/reports/pandemic-makes-politics-worse-unitesstates-case-study-0. 
Figure 1: Trends in Affective Polarization

Panel A: Nationscape (Partisans)

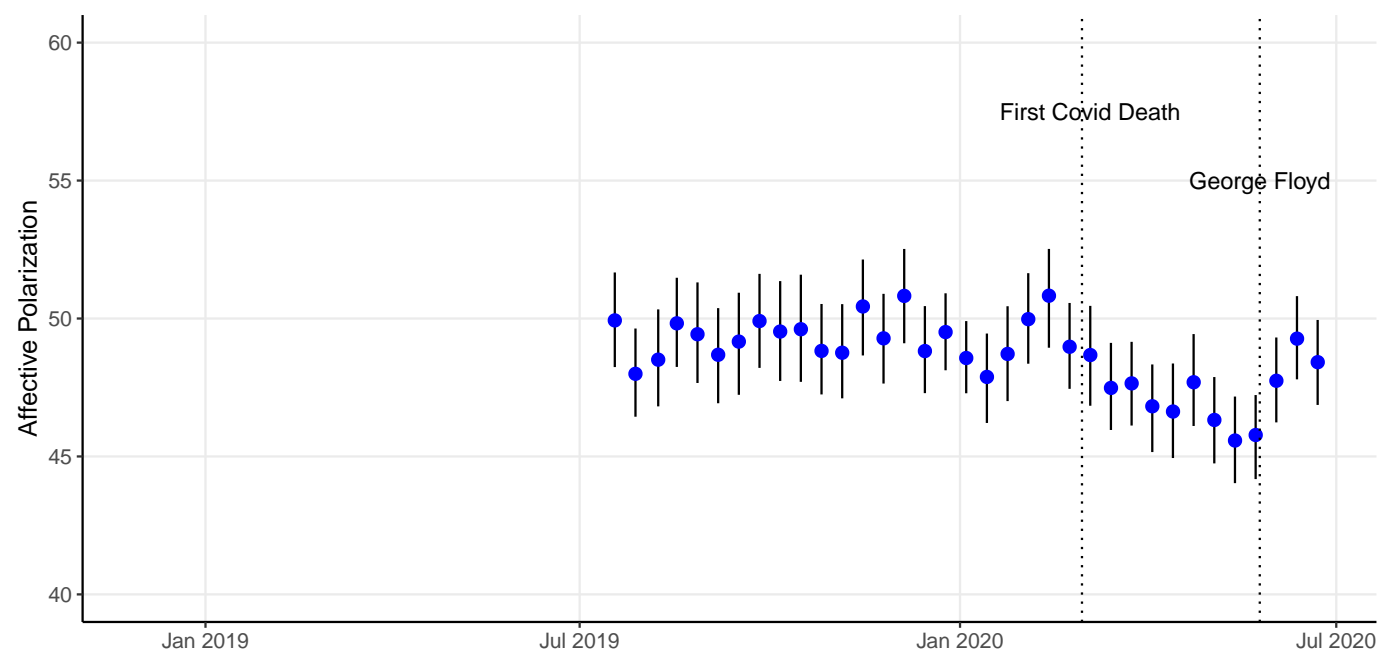

Panel B: ANES (Trump)

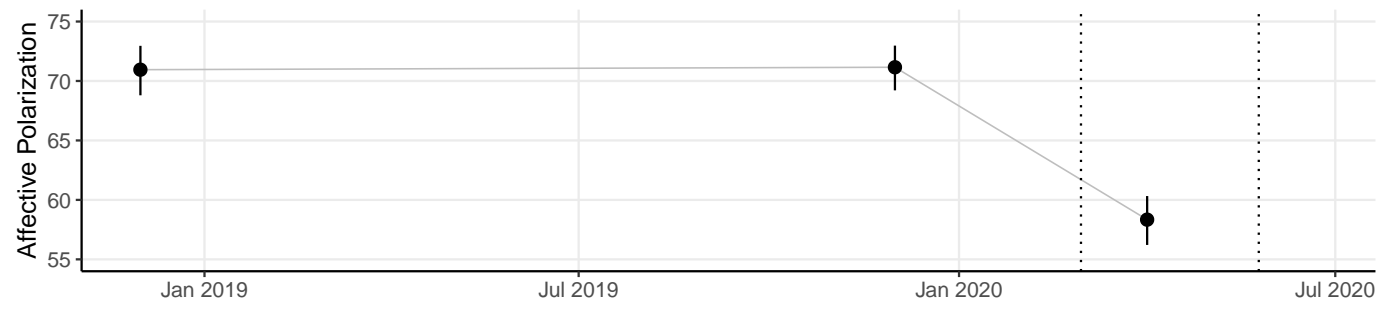

Panel C: Druckman et al. 2020 (Parties)

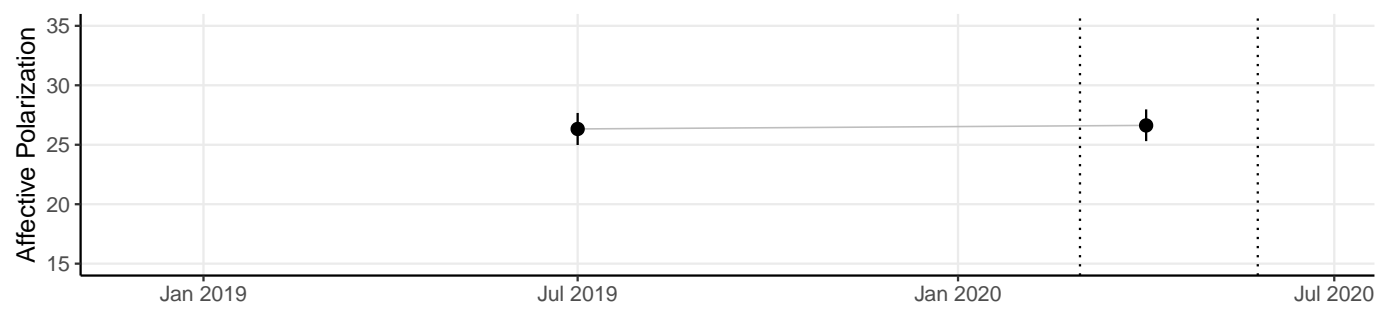

Note: Figure shows trends in affective polarization using three distinct data sources. Panel A reports affective polarization towards partisans for each ten-day period in the Nationscape data. Panel B reports the difference (Republicans minus Democrats) in average feelings towards Donald Trump from ANES surveys in December 2018, December 2019, and May 2020. Panel C reports affective polarization using a panel of respondents from Druckman et al. (2020) who completed surveys in July 2019 and April 2020. The Druckman et al. (2020) data report lower levels of affective polarization because their measures had an embedded experiment that varied the target evaluated (e.g., "Democrats," "moderate Democrats") (see Druckman et al.'s supplementary material), and restricting analysis to questions about "Democrats" (not shown) also produces a flat trend with a level more similar to the Nationscape measure. The first dashed vertical line indicates the first period in which a covid-related death was reported. The second dashed verticle line indicates the period in which George Floyd's death occurred. The .025 and .975 quantiles of a nonparametric bootstrap with 1000 replicates stratified by time period are used to construct the confidence intervals. 
Figure 2: Experimental Treatment Effects of Priming the Pandemic

\section{Panel A: Affective Polarization}

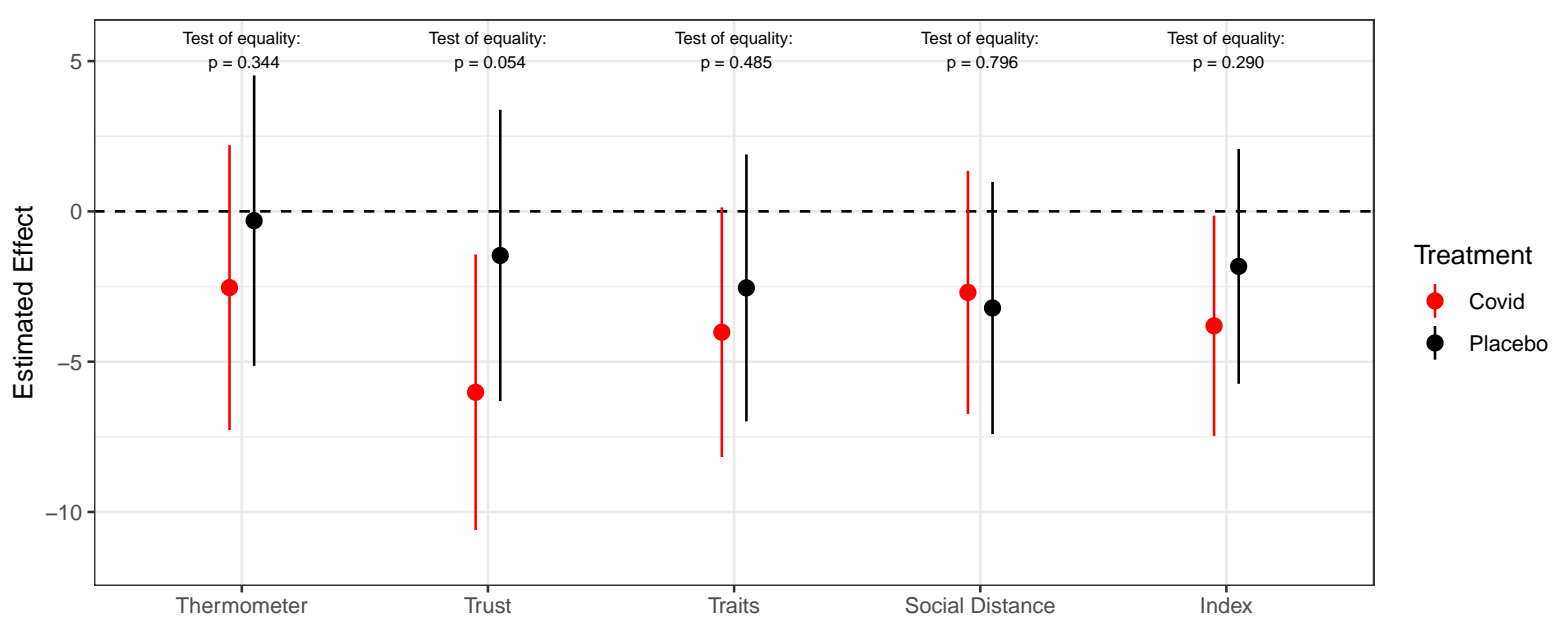

Panel B: Affect Towards Other Party

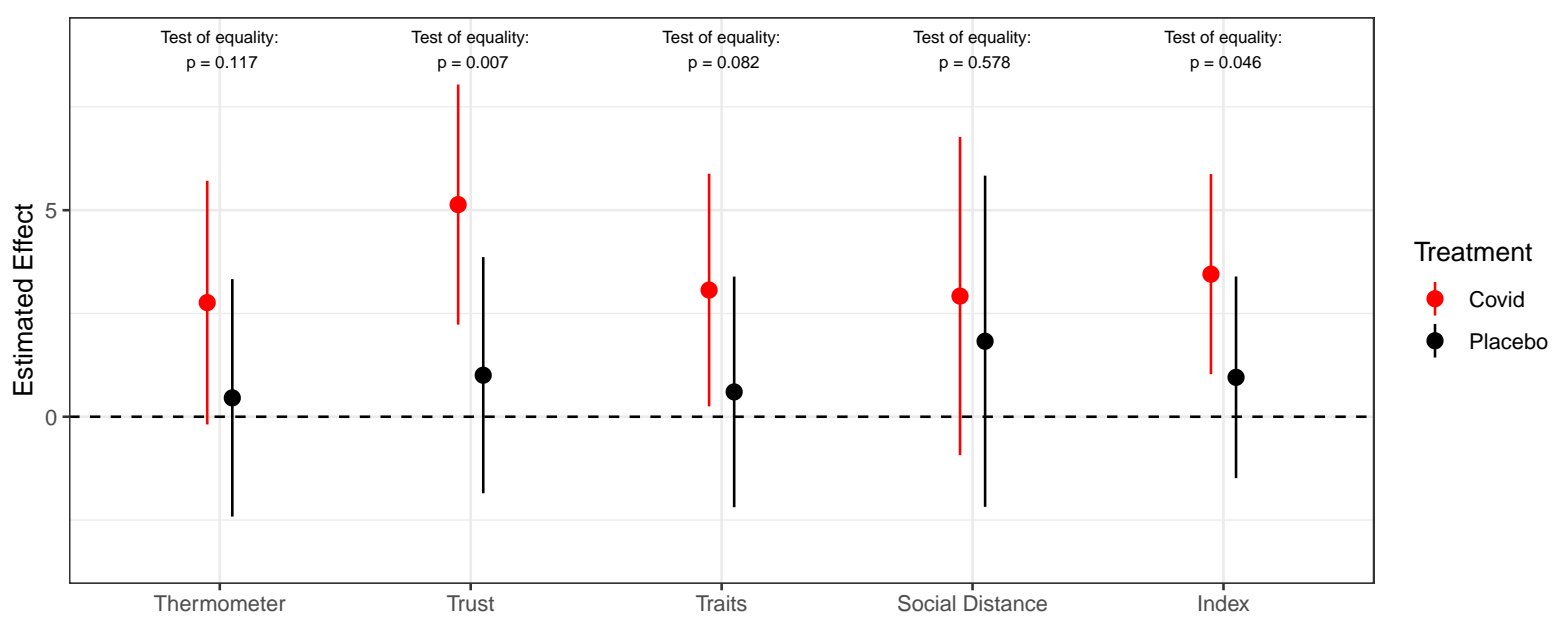

Note: Figure reports estimated treatment effects of the coronavirus and placebo primes relative to the pure control group. Panel A reports estimates on measures of affective polarization (own party minus other party). Panel B reports estimates on measures of affect towards the other party. Both panels report estimates separately for each of four question categories (feelings thermometer; trust; perceived traits; and social distance) and for an index averaging across categories. The 95 percent confidence intervals are constructed using heteroskedastic robust standard errors. Above the bars, we report the p-value from a two-sided test of equality between the coronavirus and placebo treatment effects using robust standard errors. 


\title{
SI Appendix for: Affective polarization did not increase during the coronavirus pandemic
}

\author{
Levi Boxell, Stanford University \\ Jacob Conway, Stanford University \\ James N. Druckman, Northwestern University \\ Matthew Gentzkow, Stanford University and NBER
}

October 2020 


\section{Data References}

The American National Election Studies (www.electionstudies.org). These materials are based on work supported by the National Science Foundation under grant numbers SES 1444721, 2014-2017, the University of Michigan, and Stanford University.

Tausanovitch, Chris and Lynn Vavreck. 2020. Democracy Fund + UCLA Nationscape, includes weekly surveys covering July 18, 2019-July 25, 2019 to June 25, 2020_July 2, 2020 (version 20200814). Retrieved from https://www.voterstudygroup.org/publication/nationscape-dataset.

\section{ANES Disclaimer}

The original collector of the data, ANES, and the relevant funding agency/agencies bear no responsibility for use of the data or for interpretations or inferences based upon such uses.

\section{Survey Instrument}

This section provides the full text of our survey instrument.

\section{$<$ Demographic and Background Questions $>$}

We are going to start by asking you some questions about your general attitudes and opinions.

Generally speaking, do you usually think of yourself as a Democrat, a Republican, an Independent, or what? [Democrat; Republican; Independent; Some other party]

$<$ Page seen if Democrat or Republican $>$

Would you call yourself a strong < Democrat / Republican $>$ or a not very strong < Democrat / Republican $>$ ? [Strong; Not very strong]

$<$ Page seen if Independent $>$

If you had to choose, do you think of yourself as closer to the Democratic Party or the Republican Party? [Closer to Democratic Party; Closer to Republican Party; Neither]

Which point on this scale best describes your political views? [Very liberal; Mostly liberal; Somewhat liberal; Moderate; Somewhat conservative; Mostly conservative; Very conservative] 
In general, how interested are you in politics? [Not at all interested; Not too interested; Somewhat interested; Very interested; Extremely interested]

What is the highest level of education you have completed? [Less than high school; High school graduate; Some college; 4 year college degree; Advanced degree]

What is your estimate of your family's annual household income (before taxes)? $[<\$ 30,000$; \$30,000-\$69,999; \$70,000-\$99,999; \$100,000-\$200,000; >\$200,000]

Which of the following do you consider to be your primary racial or ethnic group? Check all that apply. [White; African; American; Asian; American; Hispanic or Latino; Native American; Other]

$<$ Question seen if Other $>$ How would you describe your primary racial or ethnic group? [Text free entry]

Which of the following best describes your gender identity? [Male; Female; Transgender; None of the categories offered]

What is your age? [Under 18; 18-24; 25-34; 35-50; 51-65; Over 65]

In what state do you currently live? [Drop-down list of 50 states and Washington D.C.]

Last spring, on average, how many days a week did you read/listen/watch news about COVID19? [Never; 1 day/week; 2 days/week; 3 days/week; 4 days/week; 5 days/week; 6 days/week; Every day]

Last winter, on average, how many days a week did you read/listen/watch news about Prince Harry and Meghan Markle's separation from the royal family? [Never; 1 day/week; 2 days/week; 3 days/week; 4 days/week; 5 days/week; 6 days/week; Every day]

This is a question to just make sure you are paying attention. Please choose option $\mathrm{C}$ below, regardless of the actual answer. [A. I am enjoying this survey.; B. I do a lot of surveys.; C. I have not done many surveys.; D. None of the above.]

\section{$<$ Randomized Priming and Reflection Tasks $>$}

$<$ Each respondent is randomly assigned to one of three conditions $>$ 
$<$ Pages seen if randomly assigned to condition 1 (Covid Prime) $>$

We are going to ask how you felt about COVID-19 last spring. We also will ask you to read news articles from last spring.

$<$ Page Break>

COVID-19 swept across the United States last March and April, leading states to issue stay-athome orders. To remind you of ongoing events during this time we are next re-printing segments of two newspaper articles from March and April, 2020. We will then ask you to reflect about your experiences at that time, when the United States faced this uncertain threat.

$<$ Page Break $>$

Business Insider, March 11, 2020

The WHO officially declared the coronavirus outbreak a pandemic on March 11 after spreading to more than 100 countries around the world. "WHO has been assessing this outbreak around the clock, and we're deeply concerned both by the alarming levels of spread and severity and by the alarming levels of inaction," WHO director-general Tedros Adhanom Ghebreyesus told reporters.

USA TODAY, April 2, 2020

The world soared past the 1 million mark in confirmed coronavirus cases, jobless numbers skyrocketed, Democrats delayed their national convention and the nation's preeminent infectious disease expert required a security detail on Thursday. More bad news landed early Friday: The U.S. death toll topped 6,000 President Donald Trump and federal health officials predicted a "very painful" period in the country's fight against the public health emergency.

$<$ Page Break $>$

What were your experiences with COVID-19 last spring, as our country faced this uncertain threat? Did you have faith in the country's ability to address COVID-19 at that time (i.e., at the initial outbreak)?

Please take your time and do not rush. [Text free entry] 
$<$ Pages seen if randomly assigned to condition 2 (Placebo Prime) $>$

We are going to ask how you felt about Prince Harry and Meghan Markle stepping away from their royal duties in early 2020 . We also will ask you to read news articles from last January.

$<$ Page Break $>$

Prince Harry and Meghan Markle, after much speculation, officially stepped away from their royal duties. To remind you of ongoing events at this time we are next re-printing segments of two newspaper articles from January, 2020. We will then ask you to reflect about your experiences at that time, when they made this decision.

$<$ Page Break $>$

Business Insider, January 8, 2020

After months of speculation, Prince Harry and Meghan Markle put the rumors to rest and officially announced they were stepping down from their duties as senior royals. The Duke and Duchess of Sussex said they planned on being financially independent and split their time between North America and the United Kingdom

USA TODAY, January 9, 2020

About an hour after their announcement, another palace announcement, sent in an email from the office of the private secretary and the spokesperson for Queen Elizabeth II, landed in media inboxes. "Discussions with The Duke and Duchess of Sussex are at an early stage," the statement said carefully. "We understand their desire to take a different approach, but these are complicated issues that will take time to work through."

$<$ Page Break $>$

To the extent you followed it, what were your experiences with the royal split last winter, as the royals faced an uncertain future? Did you have faith in the UK's ability to address the royal split?

Please take your time and do not rush. [Text free entry] 
$<$ If randomly assigned to condition 3, no articles or reflection questions are seen $>$

$<$ Polarization Questions $>$

$<$ All respondents see the following questions. In these questions, " $<$ Outparty $>$ " appears as "Republican" for Democratic and Independent respondents, and as "Democratic" for Republican respondents. " $<$ Inparty >" appears as "Democratic" for Democratic and Independent respondents, and as "Republican" for Republican respondents.>

$<$ Polarization Measure: Thermometer $>$

We are now going to ask you a set of questions about the Republican and Democratic parties.

$<$ Page Break $>$

We'd like you to rate how you feel towards the Democratic and Republican parties on a scale of 0 to 100, which we call a "feeling thermometer." On this feeling thermometer scale, ratings between 0 and 49 degrees mean that you feel unfavorable and cold (with 0 being the most unfavorable/coldest). Ratings between 51 and 100 degrees mean that you feel favorable and warm (with 100 being the most favorable/warmest). A rating of 50 means you have no feelings one way or the other. How would you rate your feeling toward the Democratic and Republican parties?

the $<$ Outparty $>$ Party [0-100 Slider]

the $<$ Inparty $>$ Party [0-100 Slider]

\section{$<$ Polarization Measure: Traits $>$}

Now we'd like to know more about what you think about the $<$ Outparty $>$ Party. Below, we've given a list of words that some people might use to describe them.

For each item, please indicate how well you think it applies to the $<$ Outparty $>$ Party: 


\begin{tabular}{|c|l|l|l|l|l|}
\hline & Not at all well & Not too well & Somewhat well & Very Well & Extremely well \\
\hline \hline Patriotic & & & & & \\
\hline Intelligent & & & & & \\
\hline Honest & & & & & \\
\hline Open-minded & & & & & \\
\hline Generous & & & & & \\
\hline Hypocritical & & & & & \\
\hline Selfish & & & & & \\
\hline Mean & & & & & \\
\hline
\end{tabular}

Now we'd like to know more about what you think about the $<$ Inparty $>$ Party. Below, we've given a list of words that some people might use to describe them.

For each item, please indicate how well you think it applies to the $<$ Inparty $>$ Party: $<$ Repeat above matrix of trait questions $>$

\section{$<$ Polarization Measure: Trust $>$}

How much of the time do you think you can trust the $<$ Outparty $>$ Party to do what is right for the country? [Almost never; Once in a while; About half the time; Most of the time; Almost always]

How much of the time do you think you can trust the $<$ Inparty $>$ Party to do what is right for the country? [Almost never; Once in a while; About half the time; Most of the time; Almost always]

\section{$<$ Polarization Measure: Social Distance $>$}

How comfortable are you having close personal friends who are $<$ Outparty $>$ s? [Not at all comfortable; Not too comfortable; Somewhat comfortable; Extremely comfortable]

How comfortable are you having neighbors on your street who are $<$ Outparty $>$ s? [Not at all comfortable; Not too comfortable; Somewhat comfortable; Extremely comfortable]

Suppose a son or daughter of yours was getting married. How would you feel if he or she married a supporter of the $<$ Outparty $>$ ? [Not at all upset; Not too upset; Somewhat upset; Extremely upset] 
How comfortable are you having close personal friends who are <Inparty $>$ s? [Not at all comfortable; Not too comfortable; Somewhat comfortable; Extremely comfortable]

How comfortable are you having neighbors on your street who are $<$ Inparty $>$ s? [Not at all comfortable; Not too comfortable; Somewhat comfortable; Extremely comfortable]

Suppose a son or daughter of yours was getting married. How would you feel if he or she married a supporter of the $<$ Inparty $>$ ? [Not at all upset; Not too upset; Somewhat upset; Extremely upset] $<$ Perceived Polarization $>$

Some people say that COVID-19 caused the public to become more politically divided or polarized. Others say that it unified the public, making them less polarized. And yet others say it had no effect. What do you think? [Definitely polarized the public; Possibly polarized the public; No effect; Possibly made the public less polarized; Definitely made the public less polarized] 